\title{
3 Research Suare

\section{Quarantine Effect on Psychological Health Among People of Karachi, Pakistan Due to Pandemic of COVID-19.}

Rabeea Rizwan ( $\sim$ rabeea_rizwan@hotmail.com )

Jinnah Medical and Dental College https://orcid.org/0000-0001-6379-5099

Areeba Shaikh

Ziauddin Medical University: Ziauddin University

Shama Razzak

Jinnah Medical and Dental College

Sadaf Naqvi

Jinnah Medical and Dental College

Rosheena Nabeel Khan

United Medical and Dental College

Butool Nusrat

Ziauddin Medical University: Ziauddin University

Research

Keywords: COVID-19, depression, anxiety, stress, coronavirus, DASS-21

Posted Date: February 17th, 2021

DOI: https://doi.org/10.21203/rs.3.rs-209586/v1

License: (1) This work is licensed under a Creative Commons Attribution 4.0 International License.

Read Full License 


\section{Abstract}

Background: The coronavirus diseases (COVID-19) pandemic has been substantially affecting the life of people worldwide, especially when World Health Organization declared it as a global pandemic in the second week of March 2020. It produced momentous anguish throughout the biosphere. Apart from the increased in COVID infested reports, it instigated a considerable disturbance to psychological healthiness in the affected nations. Many nation states across the world, had executed a countrywide constrainment on all human activities and jobs to control the spread of the virus. The present study is an attempt to find out psychological distress among people residing in Pakistan during the lockdown.

Methods: Four hundred and forty three participants that were inhabitants of Karachi, Pakistan were asked to complete questionnaire. It was conducted online to maintain quarantine effect including questions about symptoms of depression, anxiety, stress, and family affluence according to Depression anxiety and stress scale 21 (DAAS-21 scale). Selection of participants was done by consecutive sampling method.

Results: The results indicated that people who were economically weak and unstable to endure the lockdown were generally affected. While awareness and fear of getting COVID-19 affluence was found to be negatively correlated with stress, anxiety, and depression. Among gender females were experiencing stress, anxiety, and depression more than males and the most affected age group were adults.

Conclusion: Moderate depression, severe anxiety and lower level of stress was seen in the population of Karachi during sudden first lockdown due to spread of COVID-19. Government officials and other establishments may take the support and corporation of professionals related to psychiatry and psychotherapy to assist in overwhelming the psychosocial problems among the homeland related to COVID-19 lockdown.

\section{Background:}

Nowadays Corona virus (COVID-19) is among the high impact respiratory pathogens from late 2019. The first case of COVID-19 emerged in Wuhan, a province in China that was reported in late 2019 (on January $10,2020)$ then in Iran on February 18,2020 (1).

Soon enough, it spread around the globe insidiously; therefore, it has been labeled as a pandemic by WHO in March 2020 (2). In Karachi, Pakistan its first case was reported on 26th February 2020 (3). The source of this disease is still dubious, and there have been many speculations as to how humans acquired this fatal virus, albeit a few studies do reveal that it may have originated from bats (4). Coronavirus, also known as SARS COV-2, spreads through direct contact, respiratory droplets, and possibly through aerosol (5).

Arrays of symptoms caused by this virus have been reported worldwide with frequent new additions to an already long list. These primarily include flu-like symptoms with a dry cough, sore throat, high fever, and 
breathing problems (6). In addition to the respiratory systems, some of the other systems affected are Central Nervous System, cardiovascular system, and Hematological system (7-9).

COVID-19 has become one of the greatest causes of distress in the healthcare system. Despite the overt advantages of strict lockdowns observed to limit the spread by flattening the curve (in 2019 to October 2020), it has its fair share of drawbacks. The risk of job maintenance, earning problems, lack of human contact, limited stress-relieving activities, and the stigma attached to the vocalization of mental health disorders seems to cause a build-up of negative emotions (10), which superimpose on the already deeprooted psychological problems faced by a myriad of people in developing countries such as Pakistan. Studies to support this claim have been conducted worldwide and they prove the rise in mental health disorders; stress, anxiety, panic, obsessive-compulsive disorder, Post-traumatic stress disorder, and depression $(11,12)$. In addition to the aforementioned mental adverse effects, the drastic and prompt modification from adhering to a proper lifestyle, to being confined to one's home, with minimal outside interaction, has led many to adopt an idle and remote lifestyle which includes lack of exercise, decreased motivation \& energy to engage in physical activities, attributed to psychological repercussions. Therefore, this might be a major cause of the rise in somatic pain, cardiovascular diseases, obesity, headache, digestive problems and insomnia $(13,14)$. This adds to the already impending burden on the health-care system. This subject matter is being rigorously explored universally, but not many efforts have been taken to delve into issues regarding the psycho-social and physical impacts in Pakistan due to COVID-19 contagion spread. Thus, this study aims to assess the physical and mental health of residents of Karachi, Pakistan as a result of lockdown

The aims of the study is to assess the mental health of people living in Karachi, Pakistan during the first initial quarantine of May 2020, to determine socio-demographic factors associated with depression, anxiety and stress during COVID-19 pandemic among general population of Karachi at age of 13 to 70 years in Karachi, Pakistan and to assess the frequency of fear of getting COVID-19 among general population of age 13 to 70 years in Karachi, Pakistan

\section{Methods:}

After ethical approval from Jinnah Medical and Dental College and Sohail University ethics committee, a cross-sectional study was conducted by a consecutive non-probability sampling technique. The sample size was calculated using Open Epi and a total of 443 samples were collected. The questionnaire was structured by using google forms web survey (Google LLC; Mountain View, CA, USA). The link to the questionnaire was sent out to the permanent resident of Karachi aged between 15-70 years by using social media like Facebook, Instagram, and WhatsApp. However, an electronic consent form was taken by the respondent before proceeding with the questionnaire. To maintain confidentiality the survey was kept anonymous and not attributable to the identity of the respondent. Once the participant clicked "submit" the response was automatically recorded and was not allowed to make any alterations to the recorded response. 
The online questionnaires were designed according to standard scoring techniques. DASS-21 (Depression, Anxiety, and Stress Scale) was used for mental health assessment questionnaire that consist of 21 questions in a set of three self-report scales designed to measure the emotional states of depression, anxiety and stress. Each of the three DASS-21 scales contains 7 items, divided into subscales with similar content.

The depression scale assessed dysphoria that is overall disappointment with life, feeling of themselves as useless, devaluation of life, self-depreciation, apathy, lack of attentiveness, dearth of general participation among people in normal daily activities, and not feeling of pleasure in pleasurable situations.

The anxiety scale assessed autonomic provocation, skeletal muscle effects, environmental anxiety, and particular feeling of apprehensive distress.

The stress scale is delicate related to stages of prolonged non-specific arousal. It assessed trouble in comforting, nervous provocation, and being certainly disappointed, disturbed, disconcerted, shorttempered, oversensitive and annoyed.

Scores for depression, anxiety and stress (DAAS) are calculated by summing the scores.

Hypothesis:

1. The extension of national lockdown may have caused deleterious effects on one's mental (health i.e. increased levels of stress, depression and anxiety) and physical health

2. The female population was more prone to have mental health issues during the lockdown

3. The male population was more likely to had negative impacts on their physical health during the lockdown

4. Young adult population was more effected than old adult population.

5. People who had children were less prone to negative mental health effects

General population with permanent residency in Karachi of age between 13-70 years and people who had access to online questionnaire were included in the study. While exclusion criteria were people who were not permanent residents of Karachi and those who do not have access to online questionnaire.

There were some limitations of the study that are; due to following standard operating procedure (SOPs) and taking preventions because of pandemic contagion COVID-19, the questionnaire was taken online and those participants who were not computer literate were not able participate in the study but a volunteer (who would be computer literate) were allowed to fill the questionnaire form in place of him/her under their presence.

\section{Data analysis plan:}

- Data was analyzed using SPSS Version 21. 
- Mean \pm SD were calculated for continuous variables.

- Frequency and proportions (\%) were calculated for categorical variables.

- Mean scores (mean \pm SD) were derived for three defined outcomes (depression, anxiety and stress) of DASS 21 scale.

- The independent t-test and ANOVA were used to assess the mean difference in mean scores of depression, anxiety and stress according to associated independent factors assessed in.

- For statistically significance, the $p$-value was kept at $<0.05$.

- Bar graph/ pie chart were created for three separate scales of DASS 21 i.e. Depression, Anxiety and Stress according to age, gender, income and education where appropriate.

\section{Sample size of your study}

\section{7 for $95 \%$ confidence}

NOTE: Though our calculated sample size was 385 but we included 443 participants in this study.

The sample size for this research was calculated using open epi software. Using the given formula;

Sample size $n=443$

Whereas confidence limit percentage selected was $5 \%$, Hypothesized \% frequency of outcome factor in the population was $50 \%$ and with a population sample of 20711000 (15).

\section{Results:}

A total of 443 participants who were permanent resident of Karachi recruited for the study from 6th May 2020 to 28th July 2020 . The mean ( \pm SD) age of the participants was $22.8( \pm 6.8)$ years. Of total, majority of the participants i.e. 338 (75.8\%) were females, while 105 (23.7\%) were male participants. Never married constituted $90.3 \%$ of all the sample while rest $9.7 \%$ were ever married including currently married, widowed and divorced.

Table 1 represents distribution of the level of depression according to the associated factors among general population of Karachi during COVID-19 pandemic. There was a significant difference of depression level among both the genders; more females were significantly having severe depression as compared to male (83.5\% vs $16.5 \%$ ) ( $p$ - value 0.045 ). Majority of the participants with no chronic illnesses (67\%) were having severe depression as compared to those having any chronic illness (33.0\%) (P-value 0.020$)$. On the contrary, more participants with family history of any disease (86.4\%) were more likely to have severe depression in comparison with those without family history of any disease (13.6\%) (P-value 0.041).

Table 2 describes the distribution of the level of anxiety according to the factors affecting it among general population. A larger population with 21 to 30 years of age (54.2\%) reported more anxiety as 
compared to participants less than 20 years $(42.6 \%)$ and $>31$ years and more (3.2\%) (P-value 0.003). Those who had household income $\leq 40,000$ PKR (37.4\%) were having more anxiety in comparison with higher income groups and the difference is statistically significant (P-value 0.009). Majority of the participants having a family history of any disease (83.2\%) showed severe depression which is statistically significant ( $P$ value 0.001 ) as opposed to those without family history of disease $(16.8 \%)$. In contrast, participants with no chronic illnesses $(67.7 \%)$ were having severe depression as compared to those having any chronic illness (32.3\%) (P-value <0.001).

Table 3 shows the distribution of the level of stress according to the factors affecting it among general population. Participants without any chronic illnesses (64.3\%) were severely depressed as compared to those who have any chronic illness $(35.7 \%)(P$-value $<0.001)$.

Figure 1 is showing the level of depression, anxiety and stress (DASS-21) among general population of Karachi, Pakistan. The moderate level of depression was reported among $43.6 \%$ of the population, whereas, severe level of anxiety was found among $35 \%$ of the study participants. Of total, $30.7 \%$ of the individuals were showing moderate level of stress measured on DASS-21 scale. 
Table 1

The distribution of the level of depression according to the associated factors among general population, Karachi, Pakistan $(n=443)$

\begin{tabular}{|c|c|c|c|c|}
\hline \multirow[t]{2}{*}{ Factors } & \multicolumn{3}{|c|}{ Depression level n (\%) } & \multirow[t]{2}{*}{ p-value } \\
\hline & Severe $\geq 15$ & Moderate 10-14 & Normal 1-9 & \\
\hline Age & & & & 0.189 \\
\hline$\leq 20$ years & $37(35.9)$ & $67(34.7)$ & $39(26.5)$ & \\
\hline 21 to 30 years & $63(61.2)$ & $112(58.0)$ & $95(64.6)$ & \\
\hline$\geq 31$ years & $3(2.9)$ & $14(7.3)$ & $13(8.8)$ & \\
\hline Gender & & & & 0.045 \\
\hline Male & $17(16.5)$ & $44(22.8)$ & $44(29.9)$ & \\
\hline Female & $86(83.5)$ & 149 (77.2) & $103(70.1)$ & \\
\hline Household Income & & & & 0.714 \\
\hline$\leq 40,000$ PKR & $31(30.1)$ & $55(28.5)$ & $34(23.1)$ & \\
\hline 40,001 to 100,000 PKR & $37(35.9)$ & $75(38.9)$ & $58(39.5)$ & \\
\hline$\geq 100,000$ PKR & $35(34.0)$ & $63(32.6)$ & $55(37.4)$ & \\
\hline Any Chronic illness & & & & 0.020 \\
\hline None & $69(67.0)$ & $147(76.2)$ & $121(82.3)$ & \\
\hline Yes & $34(33.0)$ & $46(23.8)$ & $26(17.7)$ & \\
\hline Family history of any disease & & & & 0.041 \\
\hline None & $14(13.6)$ & $28(14.5)$ & $35(23.8)$ & \\
\hline Yes & $89(86.4)$ & $165(85.5)$ & $112(76.2)$ & \\
\hline Aware of COVID-19 & & & & 0.044 \\
\hline No & $01(1.0)$ & $02(1.0)$ & $07(4.8)$ & \\
\hline Yes & $102(99.0)$ & 191 (99.0) & $140(95.2)$ & \\
\hline Fear of COVID-19 & & & & 0.532 \\
\hline Low & 39 (37.9) & 68 (35.2) & $61(41.5)$ & \\
\hline Neutral & $33(32.0)$ & $57(29.5)$ & 47 (32.0) & \\
\hline High & $31(30.1)$ & 68 (35.2) & $39(26.5)$ & \\
\hline Use of PPE & & & & 0.438 \\
\hline
\end{tabular}




\begin{tabular}{|llll|}
\hline Factors & \multicolumn{2}{l}{ Depression level $\mathbf{n}(\%)$} & p-value \\
\cline { 2 - 4 } & Severe $\geq \mathbf{1 5}$ & Moderate 10-14 & Normal 1-9 \\
\hline Never & $18(17.5)$ & $22(11.4)$ & $15(10.2)$ \\
\hline Sometimes & $45(43.7)$ & $83(43.0)$ & $64(43.5)$ \\
\hline Always & $40(38.8)$ & $88(45.6)$ & $68(46.3)$ \\
\hline
\end{tabular}


Table 2

The distribution of the level of anxiety according to the associated factors among general population, Karachi, Pakistan $(n=443)$

\begin{tabular}{|c|c|c|c|c|}
\hline \multirow[t]{2}{*}{ Factors } & \multicolumn{3}{|c|}{ Anxiety level n (\%) } & \multirow[t]{2}{*}{ p-value } \\
\hline & Severe $\geq 15$ & Moderate 1-14 & Normal 1-9 & \\
\hline Age & & & & 0.003 \\
\hline$\leq 20$ years & $66(42.6)$ & $42(28.6)$ & $35(24.8)$ & \\
\hline 21 to 30 years & $84(54.2)$ & 95 (64.6) & $91(64.5)$ & \\
\hline$\geq 31$ years & $5(3.2)$ & $10(6.8)$ & $15(10.3)$ & \\
\hline Gender & & & & 0.252 \\
\hline Male & $30(19.4)$ & $36(24.5)$ & $39(27.7)$ & \\
\hline Female & $125(80.6)$ & $111(75.5)$ & $102(72.3)$ & \\
\hline Household Income & & & & 0.009 \\
\hline$\leq 40,000$ PKR & $58(37.4)$ & $33(22.4)$ & $29(20.6)$ & \\
\hline 40,001 to 100,000 PKR & $52(33.5)$ & $62(42.2)$ & $56(39.7)$ & \\
\hline$\geq 100,000$ PKR & $45(29.1)$ & $52(35.4)$ & $56(39.7)$ & \\
\hline Any Chronic illness & & & & 0.000 \\
\hline None & $105(67.7)$ & $109(74.1)$ & $123(87.2)$ & \\
\hline Yes & $50(32.3)$ & $38(25.9)$ & $18(12.8)$ & \\
\hline Family history of any diseases & & & & 0.001 \\
\hline None & $26(16.8)$ & $14(9.5)$ & $37(26.2)$ & \\
\hline Yes & $129(83.2)$ & $133(90.5)$ & $104(73.8)$ & \\
\hline Aware of COVID-19 & & & & 0.118 \\
\hline No & $03(1.9)$ & $01(0.7)$ & $06(4.3)$ & \\
\hline Yes & $152(98.1)$ & $146(99.3)$ & $135(95.7)$ & \\
\hline Fear of COVID-19 & & & & 0.816 \\
\hline Low & $55(35.5)$ & $58(39.5)$ & 55 (39.0) & \\
\hline Neutral & $47(30.3)$ & 48 (32.7) & $42(29.8)$ & \\
\hline High & $53(34.2)$ & $41(27.9)$ & $44(31.2)$ & \\
\hline Use of PPE & & & & 0.192 \\
\hline
\end{tabular}




\begin{tabular}{|llll|}
\hline Factors & \multicolumn{2}{l}{ Anxiety level $\mathbf{n}(\%)$} & p-value \\
\cline { 2 - 4 } & Severe $\geq \mathbf{1 5}$ & Moderate 1-14 & Normal 1-9 \\
\hline Never & $23(14.8)$ & $20(13.6)$ & $12(8.5)$ \\
\hline Sometimes & $61(39.4)$ & $71(48.3)$ & $60(42.6)$ \\
\hline Always & $71(45.8)$ & $56(38.1)$ & $69(48.9)$ \\
\hline
\end{tabular}


Table 3

The distribution of the level of stress according to the associated factors among general population, Karachi, Pakistan $(n=443)$

\begin{tabular}{|c|c|c|c|c|}
\hline \multirow[t]{2}{*}{ Factors } & \multicolumn{3}{|c|}{ Stress level n (\%) } & \multirow[t]{2}{*}{ p-value } \\
\hline & Severe & Moderate & Normal & \\
\hline Age & & & & 0.259 \\
\hline$\leq 20$ years & $35(41.7)$ & $43(31.6)$ & $65(29.1)$ & \\
\hline 21 to 30 years & $46(54.8)$ & $83(61.0)$ & $141(63.2)$ & \\
\hline$\geq 31$ years & $3(3.6)$ & $10(7.4)$ & $17(7.6)$ & \\
\hline Gender & & & & 0.082 \\
\hline Male & $14(16.7)$ & $28(20.6)$ & $63(28.3)$ & \\
\hline Female & $70(83.3)$ & $108(79.4)$ & $160(71.7)$ & \\
\hline Household Income & & & & 0.605 \\
\hline$\leq 40,000$ PKR & $25(29.8)$ & $41(30.1)$ & $54(24.2)$ & \\
\hline 40,001 to $100,000 \mathrm{PKR}$ & $29(34.5)$ & $48(35.3)$ & $93(41.7)$ & \\
\hline$\geq 100,000 \mathrm{PKR}$ & $30(35.7)$ & $47(34.6)$ & $76(34.1)$ & \\
\hline Any Chronic illness & & & & 0.000 \\
\hline None & $54(64.3)$ & $95(69.9)$ & $188(84.3)$ & \\
\hline Yes & $30(35.7)$ & $41(30.1)$ & $35(15.7)$ & \\
\hline Family history of any diseases & & & & 0.112 \\
\hline None & 9 (10.7) & $22(16.2)$ & $46(20.6)$ & \\
\hline Yes & $75(89.3)$ & $114(83.8)$ & $177(79.4)$ & \\
\hline Aware of COVID-19 & & & & 0.330 \\
\hline No & $02(2.4)$ & $01(0.7)$ & $07(3.1)$ & \\
\hline Yes & $82(97.6)$ & 135 (99.3) & $216(96.9)$ & \\
\hline Fear of COVID-19 & & & & 0.404 \\
\hline Low & $32(38.1)$ & $56(41.2)$ & 80 (35.9) & \\
\hline Neutral & $25(29.8)$ & $34(25.0)$ & 78 (35.0) & \\
\hline High & $27(32.1)$ & $46(33.8)$ & 65 (29.1) & \\
\hline Use of PPE & & & & 0.129 \\
\hline
\end{tabular}




\begin{tabular}{|llll|}
\hline Factors & \multicolumn{2}{l}{ Stress level $\mathbf{n}(\%)$} & p-value \\
\cline { 2 - 4 } & Severe & Moderate & Normal \\
\hline Never & $15(17.9)$ & $18(13.2)$ & $22(9.9)$ \\
\hline Sometimes & $37(44.0)$ & $50(36.8)$ & $105(47.1)$ \\
\hline Always & $32(38.1)$ & $68(50.0)$ & $96(43.0)$ \\
\hline
\end{tabular}

\section{Discussion:}

COVID-19 is the most calamitous and challenging public health crises since influenza outbreak in 1918. As of 14th May 2020, more than 4.2 million people have been infected and 292046 succumbed to it globally (WHO, 2020). It has brought pain and suffering to the nations worldwide. The undeniable fact is that the disease is causing great deal of anxiety, fear and unrest in people of all ages. University and college students too were no exception as it has been almost two months when all the education institutions got closed due to COVID-19 in Pakistan (Order No. SO (I\&C-I) 1-2/2020). There was strict complete lock down during the period.

The distribution of the level of depression according to the associated factors among general population, Karachi, Pakistan $(n=443)$

There was no significant difference found between males and females for depression and anxiety; however, females had significantly higher stress scores compared to males. According to this present data (collected from May to July 2020) it was analyzed that among both genders the females of Karachi city had higher level of depression (83.5\%, p - value 0.045 ) during first lockdown (from March to August $2020)$ due to spread of Corona virus among population $(15,16)$ which is similar to the findings of other studies where $71 \%$ severe depression in another city of Pakistan and $85 \%$ in Tunisia was found utmost among female gender(17-20). As it is known that usually females are psychologically more sensitive by the pandemics and the other sudden changes in life (18). The high levels of depression and anxiety in them could be because of several influences like hormonal variations, manifestation of feelings and opinions concerning their communal circumstances. (21-23). Generally she is the foremost custodian and care taker of her family and house. She has more domestic responsibilities and for taking care of children and elders in her family. Therefore increase in her daily responsibilities during sudden lockdown could depressed her more(24).

This recent study (Table 2) notifies that the severe anxiety (54.2\%, p-value 0.003$)$ and depression (63, $61.2 \%)$ was found most in participants at age of 21-30 years and least in people > 30 years $13(8.8 \%)$ which was also noted among people who were the permanent residents of Punjab province, Pakistan with higher depression 574 (50.6\%) at age range of 20 to 25 year(17).Young age people seemed more symptoms of depression this may due to their greater exposure of gathering information to screen time like television, news media, and news softwares etc. that were further eliciting their stress and depression 
$(25,26)$. Additionally it was also noticed that studies oriented stress which was due to change in face to face interactive lectures to online lectures/classes with no direct social interaction with their teachers, facilitators, class fellows and friends, stopped institutional physical activities, internet connection problems, insufficient home resources for online learning/classes as all people are not stable economically and other problems which disturbed their studies (27-29). This age group are concerned over the future consequences and economic challenges caused by the pandemic, as they are key active working forces in a society and are, therefore, mostly affected by redundancies and business closures. Some researchers have argued that a greater anxiety among young people may be due to their greater access to information through social media, which can also cause stress $(28,30)$. Additionally, while rendering to a study of China, greater symptoms of psychological disturbance usually seen in individuals with higher education levels that is for the reason that of their greater self-consciousness in regard to their personal fitness and well-being (31).

The recent data also showed the strong association of severe depression (67\%, p-value 0.020$)$ and anxiety $(64.3 \%$, p-value 0.000$)$ among the participants who were had no chronic illness and who had family history of any disease ( $86.4 \%$, p-value 0.041 ) which is in contrast to the people of Australia and Netherlands, those who had chronic illness was observed in association with anxiety $(2.7 \pm 3.7)$, depression $(5.0 \pm 5.2)$ and stress $(5.5 \pm 4.9)$ in comparison to the people who had healthy background (32). Recent studies have revealed an association between medical history and increased anxiety and depression caused by the COVID-19 spread. While in association with studies of Italy and China, history of chronic illness was found to be significantly associated with higher IES-R, DASS stress subscale, DASS anxiety subscale, and DASS depression subscale scores $p$ value $<0.005(33-35)$. The purpose of increase in mental disturbance and stress among people in relation with chronic illness during lockdown are due to many factors particularly it is related to their low socioeconomic status, elder age and live single or separated from family in addition with comorbidities, polypharmacy and fear of getting additional severity of COVID-19 outcomes. Those who have chronic co-morbidities but no psychological impact during lockdown, this may due to that they already has suffered from mental issues during their illness period and now they have adapted to face such types of situations .

The possible reason could be the direct effect of the co-morbid medical condition, medication used to treat medical illness, illness related anxiety or stress related to longer duration, and the severity of COVID19 outcome among those who have another chronic medical condition and longer duration of illness (36). Many literatures have clearly provided evidence on association of occupation/jobs and income on one's mental health. However the present study showed that participants who had household income $\leq$ $40,000$ PKR had more anxiety (37.4\% P-value 0.009$)$ but severe depression $37(35.9 \%)$ in those who had household income of 40,001 to 100,000 Pak R.s/month. While among the people of Australia with lowest income $<\$ 1000 /$ week had higher depression $5.2( \pm 5.7)$, anxiety $2.6( \pm 3.7)$ and stress $4.9( \pm 5.0)$ during this lockdown (32). Thus, financial constraint is one of the factor that influenced on human psychological morbidities during seclusion period that is due to limited provisions to sustain for themselves and their family (37). Thus, financial constraint is one of the factor that influenced on human psychological 
morbidities during seclusion period that is due to limited provisions to sustain for themselves and their family (37).

\section{Conclusion:}

Overall, moderate depression, severe anxiety and lower level of stress was seen in Karachi population. Among gender females were the most that were affected by the first strict complete lock down period along with the adult age group. Study highlights the depression, anxiety and stress of Karachiites were predominantly highly associated with chronic ailments. Those with family history of any sickness were also revealed with severe depression and anxiety. While regarding occupation and income wise, those people were more effected mentally with severe anxiety whose monthly income was less the forty thousand Pakistani rupees. However, those whose income was greater than one lac suffered with severe stress with no significant p-value.

\section{Declarations:}

\section{Authors' contributions}

All authors participated in the study at extensive rate. RR, AS designed the manuscript. AS collected data and wrote research proposal with RR. SR analyzed the data and wrote results, RR wrote the article, SN and RNK edited and reviewed the article.

\section{Ethics approval and consent to participate.}

The study was approved by Ethics Review Committee of Jinnah Medical and Dental College, Karachi, Pakistan. The protocol number is $00057 / 20$. Online informed consent was taken before the questionnaire started.

\section{Competing interests}

The data is original and not copied from any resources.

\section{Funding}

Not required

\section{Acknowledgements}

Not required

\section{References:}

1. Nuzzo J, Mullen L, Snyder M, Cicero A, Inglesby T. Preparedness for a high-impact respiratory pathogen pandemic. Baltimore, MD, USA: Johns Hopkins Center for Health Security. 2019. 
2. Flaherty GT, Hession P, Liew CH, Lim BCW, Leong TK, Lim V, et al. COVID-19 in adult patients with preexisting chronic cardiac, respiratory and metabolic disease: a critical literature review with clinical recommendations. Tropical diseases, travel medicine and vaccines. 2020;6(1):1-13.

3. Waris A, Khan AU, Ali M, Ali A, Baset A. COVID-19 outbreak: current scenario of Pakistan. New Microbes and New Infections. 2020:100681.

4. Liu P, Jiang J-Z, Wan X-F, Hua Y, Li L, Zhou J, et al. Are pangolins the intermediate host of the 2019 novel coronavirus (SARS-CoV-2)? PLoS Pathogens. 2020;16(5):e1008421.

5. Ge Z-y, Yang L-m, Xia J-j, Fu X-h, Zhang Y-z. Possible aerosol transmission of COVID-19 and special precautions in dentistry. Journal of Zhejiang University-SCIENCE B. 2020:1-8.

6. Ali I, Alharbi OM. COVID-19: Disease, management, treatment, and social impact. Science of the Total Environment. 2020:138861.

7. Carod-Artal F. Neurological complications of coronavirus and COVID-19. Revista de Neurologia. 2020;70(9):311-22.

8. Zhu H, Rhee J-W, Cheng P, Waliany S, Chang A, Witteles RM, et al. Cardiovascular complications in patients with COVID-19: consequences of viral toxicities and host immune response. Current cardiology reports. 2020;22:1-9.

9. Helms J, Tacquard C, Severac F, Leonard-Lorant I, Ohana M, Delabranche X, et al. High risk of thrombosis in patients with severe SARS-CoV-2 infection: a multicenter prospective cohort study. Intensive care medicine. 2020:1-10.

10. Fegert JM, Vitiello B, Plener PL, Clemens V. Challenges and burden of the Coronavirus 2019 (COVID19) pandemic for child and adolescent mental health: a narrative review to highlight clinical and research needs in the acute phase and the long return to normality. Child and adolescent psychiatry and mental health. 2020;14:1-11.

11. Jakovljevic M, Bjedov S, Jaksic N, Jakovljevic I. COVID-19 pandemia and public and global mental health from the perspective of global health security. Psychiatria Danubina. 2020;32(1):6-14.

12. Hamza Shuja K, Aqeel M, Jaffar A, Ahmed A. COVID-19 pandemic and impending global mental health implications. Psychiatria Danubina. 2020;32(1):32-5.

13. Chandrasekaran B, Ganesan TB. Sedentarism and chronic disease risk in COVID 19 lockdown-a scoping review. Scottish Medical Journal. 2020:0036933020946336.

14. Majumdar P, Biswas A, Sahu S. COVID-19 pandemic and lockdown: cause of sleep disruption, depression, somatic pain, and increased screen exposure of office workers and students of India. Chronobiology International. 2020;37(8):1191-200.

15. Nawaz A, Su X, Iqbal S, Zahoor H, Asad A, Asghar S, et al. Validating a Phenomenological Mathematical Model for Public Health and Safety Interventions Influencing the Evolutionary Stages of Recent Outbreak for Long-Term and Short-Term Domains in Pakistan. Complexity. 2020;2020.

16. Nafees M, Khan F. Pakistan's Response to COVID-19 Pandemic and Efficacy of Quarantine and Partial Lockdown: Facts. Hopes and Expectations nd. 
17. Salman M, Asif N, Mustafa ZU, Khan TM, Shehzadi N, Hussain K, et al. Psychological Impact of COVID-19 on Pakistani University Students and How They Are Coping. medRxiv. 2020.

18. Rabbani F, Khan HA, Piryani S, Khan AR, Abid F. Psychological and social impact of COVID-19 in Pakistan: Need for Gender Responsive Policies. medRxiv. 2020.

19. Sediri S, Zgueb Y, Ouanes S, Ouali U, Bourgou S, Jomli R, et al. Women's mental health: acute impact of COVID-19 pandemic on domestic violence. Archives of women's mental health. 2020:1-8.

20. Al Omari O, Al Sabei S, Al Rawajfah O, Abu Sharour L, Aljohani K, Alomari K, et al. Prevalence and predictors of depression, anxiety, and stress among youth at the time of CoViD-19: an online crosssectional multicountry study. Depression research and treatment. 2020;2020.

21. Aneshensel CS, Phelan JC, Bierman A. The sociology of mental health: Surveying the field. Handbook of the sociology of mental health: Springer; 2013. p. 1-19.

22. Goldstein JM, Jerram M, Poldrack R, Ahern T, Kennedy DN, Seidman LJ, et al. Hormonal cycle modulates arousal circuitry in women using functional magnetic resonance imaging. Journal of Neuroscience. 2005;25(40):9309-16.

23. Elhai JD, Yang H, McKay D, Asmundson GJ. COVID-19 anxiety symptoms associated with problematic smartphone use severity in Chinese adults. Journal of Affective Disorders. 2020.

24. Vigouroux SL, Scola C. Differences in parental burnout: influence of demographic factors and personality of parents and children. Frontiers in psychology. 2018;9:887.

25. Bao Y, Sun Y, Meng S, Shi J, Lu L. nCoV epidemic: address mental health care to empower society. Lancet [Internet]. 2020 [citado 16/4/2020]; 395 (10224). 2019.

26. Huang Y, Zhao N. Generalized anxiety disorder, depressive symptoms and sleep quality during COVID-19 outbreak in China: a web-based cross-sectional survey. Psychiatry research. 2020:112954.

27. Antúnez Z, Vinet EV. Escalas de depresión, ansiedad y Estrés (DASS-21): Validación de la Versión abreviada en Estudiantes Universitarios Chilenos. Terapia psicológica. 2012;30(3):49-55.

28. Raj U, Fatima A. Stress in Students after Lockdown Due to COVID-19 Thereat and the Effects of Attending Online Classes. Available at SSRN 3584220. 2020.

29. AlAteeq DA, Aljhani S, AlEesa D. Perceived stress among students in virtual classrooms during the COVID-19 outbreak in KSA. Journal of Taibah University Medical Sciences. 2020;15(5):398-403.

30. Wahed WYA, Hassan SK. Prevalence and associated factors of stress, anxiety and depression among medical Fayoum University students. Alexandria Journal of medicine. 2017;53(1):77-84.

31. Holmes EA, O'Connor RC, Perry VH, Tracey I, Wessely S, Arseneault L, et al. Multidisciplinary research priorities for the COVID-19 pandemic: a call for action for mental health science. The Lancet Psychiatry. 2020.

32. Stanton R, To QG, Khalesi S, Williams SL, Alley SJ, Thwaite TL, et al. Depression, anxiety and stress during COVID-19: associations with changes in physical activity, sleep, tobacco and alcohol use in Australian adults. International journal of environmental research and public health. 2020;17(11):4065. 
33. Deledda G, Riccardi N, Gori S, Poli S, Giansante M, Geccherle E, et al. The Impact of the SARS-CoV-2 Outbreak on the Psychological Flexibility and Behaviour of Cancelling Medical Appointments of Italian Patients with Pre-Existing Medical Condition: The "ImpACT-COVID-19 for Patients" MultiCentre Observational Study. International Journal of Environmental Research and Public Health. 2021;18(1):340.

34. Demartini B, Nisticò V, D'Agostino A, Priori A, Gambini O. Early psychiatric impact of COVID-19 pandemic on the general population and healthcare workers in Italy: a preliminary study. Frontiers in psychiatry. 2020;11.

35. Si M, Su X-Y, Jiang Y, Wang W-J, Gu X-F, Ma L, et al. Psychological Impact and Associated Factors During the Containment Stage of Covid-19 Epidemic Among College Students in China. 2020.

36. Hajure M, Tariku M, Mohammedhussein M, Dule A. Depression, anxiety and associated factors among chronic medical patients amid COVID-19 pandemic in Mettu Karl Referral Hospital, Mettu, Ethiopia, 2020. Neuropsychiatric disease and treatment. 2020;16:2511.

37. Wang G-Y, Tang S-F. Perceived psychosocial health and its sociodemographic correlates in times of the COVID-19 pandemic: a community-based online study in China. Infectious diseases of poverty. 2020;9(1):1-10.

\section{Figures}

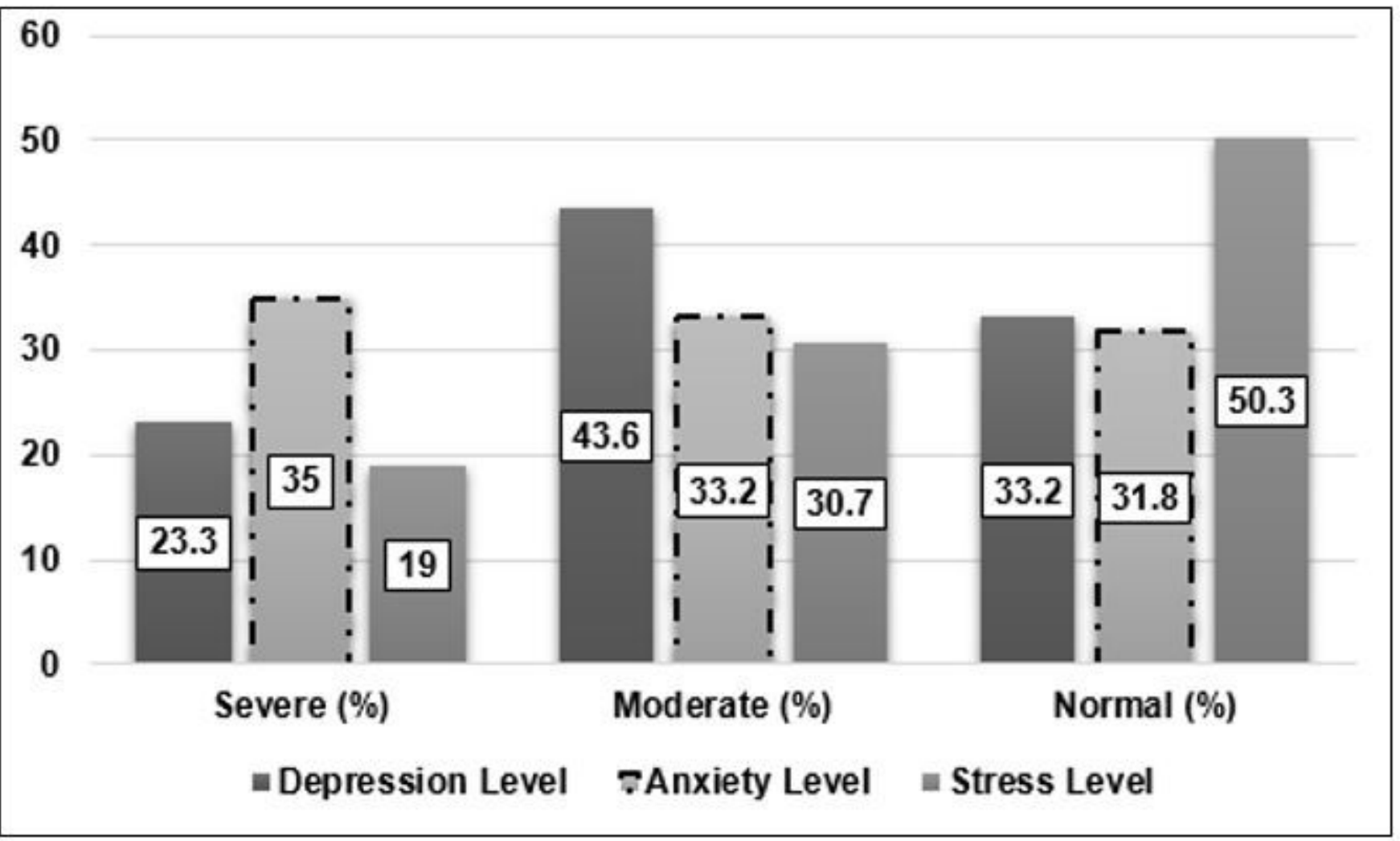

Figure 1 
the level of depression, anxiety and stress (DASS-21) among general population of Karachi, Pakistan. 